\title{
Clinical and electrophysiological observations in patients with low pressure retinopathy
}

\author{
R W ROSS RUSSELL' AND H IKEDA ${ }^{2}$ \\ From the 'Medical Eye Unit and ${ }^{2} V$ ision Research Unit of the Sherrington School, the Rayne Institute, \\ St Thomas's Hospital, London
}

SUMmaRY The clinical, angiographic, and electrophysiological features of seven patients with transient visual loss and low-pressure retinopathy are presented. Six of the patients also had symptoms of cerebral ischaemia. The commonest provoking feature was bright light. Angiography showed multiple extracranial occlusions involving both internal and external carotid arteries in addition to occlusion or stenosis on the contralateral side. Electroretinography showed delay in the recovery of the $b$ wave in the affected eye after exposure to bright light. This appears to be a valuable test for the detection of minor degrees of ischaemic damage to the retina caused by insufficiency of the retinal and choroidal circulation.

Kearns and Hollenhorst ${ }^{1}$ first pointed out that an unusual type of haemorrhagic retinopathy (venous stasis retinopathy) may occur in patients with carotid artery occlusion from perfusion of the retina at an abnormally low arterial pressure. If unrelieved the condition may progress to loss of sight from the

Correspondence to $\operatorname{Dr} \mathrm{R}$ W Ross Russell, Department of Neurology, St Thomas's Hospital, London SE1 7EH. ischaemic and haemorrhagic consequences of vascular closure and neovascularisation; the anterior segment of the eye may also become involved. ${ }^{2}$

Increasing use of digital subtraction angiography has identified many patients with unsuspected multiple extracranial artery disease at the time when they have suffered only minor symptoms. This report reviews the clinical features of seven patients with episodic visual loss caused by temporary retinal

Table 1 Clinical and angiographic featuresof low pressure retinopathy

\begin{tabular}{|c|c|c|c|c|c|c|}
\hline Patient & Sex & Age & Arterial lesion & Transient visual symptoms & Provocation & Other features \\
\hline 1 & $\mathbf{M}$ & 70 & $\begin{array}{l}\text { Atheroma: LIC occlusion } \\
\text { RIC stenosis }\end{array}$ & $\begin{array}{l}\text { Daily, uniocular L eye; } \\
\text { fragmentation, excessive } \\
\text { contrast }\end{array}$ & $\begin{array}{l}\text { Light, heat, standing, } \\
\text { exertion }\end{array}$ & $\begin{array}{l}\text { No cerebral symptoms, } \\
\text { cerebral border zone } \\
\text { infarct }(\mathrm{CT})\end{array}$ \\
\hline 2 & $\mathbf{F}$ & 59 & Atheroma: LCC occlusion & $\begin{array}{l}\text { 1-2/day uniocular L eye; } \\
\text { blurring }\end{array}$ & Light, standing, walking & $\begin{array}{l}\text { 'Tonic' L pupil, L } \\
\text { hemisphere TIA and } \\
\text { completed stroke }\end{array}$ \\
\hline 3 & $\mathbf{M}$ & 72 & $\begin{array}{l}\text { Atheroma: bilateral ICA } \\
\text { occlusion }\end{array}$ & |Both eyes; dazzle & Light & $\begin{array}{l}\text { TIA unilateral L 'tonic' } \\
\text { pupils }\end{array}$ \\
\hline 4 & $\mathbf{M}$ & 62 & $\begin{array}{l}\text { Atheroma: LCC occlusion } \\
\text { RIC stenosis }\end{array}$ & $\begin{array}{l}\text { Two per week uniocular } L \\
\text { eye; flashing lights frosted } \\
\text { glass }\end{array}$ & Light, looking upwards & TIA L hemisphere \\
\hline 5 & $\mathbf{F}$ & 53 & Atheroma: RIC occlusion & $\begin{array}{l}\text { Daily, uniocular } \mathrm{R} \text { eye; } \\
\text { central coloured flashing, } \\
\text { fragmentation }\end{array}$ & Light & $\begin{array}{l}\text { TIAs and completed stroke } \\
(\mathrm{CT}), \text { border zone } \\
\text { infarct }\end{array}$ \\
\hline 6 & $\mathbf{M}$ & 59 & $\begin{array}{l}\text { Atheroma: RIC occlusion } \\
\text { REC stenosis }\end{array}$ & $\begin{array}{l}\text { Recurrent uniocular R eye; } \\
\text { blurring }\end{array}$ & $\pi$ & $\begin{array}{l}\text { Localised infarct } \mathbf{R} \\
\text { hemisphere }\end{array}$ \\
\hline 7 & $\mathbf{M}$ & 54 & $\begin{array}{l}\text { Atheroma: LCC occlusion } \\
\text { RIC stenosis }\end{array}$ & $\begin{array}{l}\text { Daily dazzling L eye; } \\
\text { contrasting kaleidoscope } \\
\text { contraction of field }\end{array}$ & $\begin{array}{l}\text { Heat, sunshine, looking } \\
\text { upwards, neck extension, } \\
\text { hot meal }\end{array}$ & TIA L hemisphere \\
\hline
\end{tabular}

LIC, RIC= left, right internal carotid artery. $\mathrm{LCC}, \mathrm{RCC}=$ left, right common carotid artery. ICA = internal carotid artery.

REC = right external carotid artery. TIA = transient ischaemic attack. $C T=$ computer tomography. 
insufficiency. The diagnostic value of the electroretinogram (ERG) is emphasised: it may point to the underlying mechanism causing transient loss of sight.

\section{Patients and methods}

The seven patients described here were selected from a total of 23 patients having venous stasis retinopathy. The remainder either had no visual symptoms or a fixed visual deficit.

\section{Results}

VISUAL SYMPTOMS (Table 1)

Our patients had transient visual disturbances, uniocular in six and binocular (at different times) in one. In five patients the attacks consisted of a distortion, fragmentation, or dazzling sensation. They described visual images as excessively 'contrasty' as in an incorrectly developed negative film. In addition brief central flashes of light were experienced by two patients. The remaining two patients simply described the attacks as temporary blurring of vision without special features.

The visual symptoms developed over half to one minute and continued for five to 15 minutes.

All the patients were questioned about the circumstances of onset of their attacks and for environmental events which could provoke symptoms (Table 1). Six of the seven patients noticed provocation of attacks by bright light, especially on going out into strong sunlight. Two patients mentioned postural factors such as suddenly standing upright or the onset of exertion. Two found attacks to occur on upward movement of the eyes and one on extension of the neck. Only one patient felt that the attacks occurred at random.

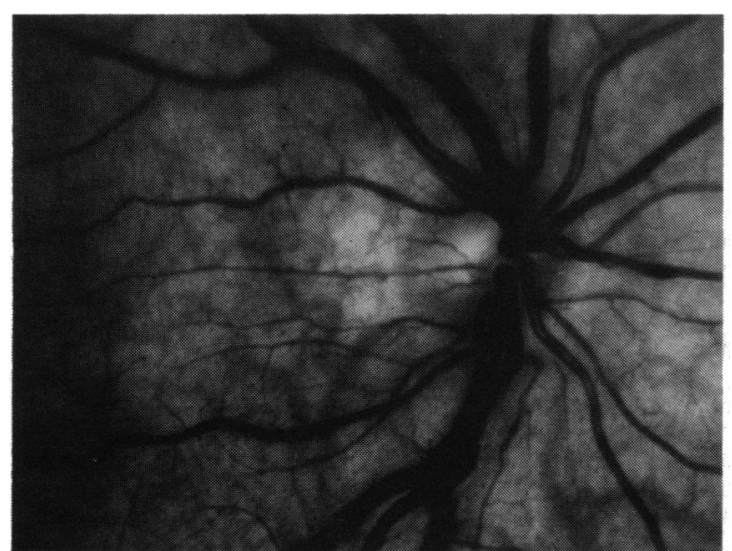

Fig. 1 Right venous stasis retinopathy. A: Right retina disc region to show venous dilatation.
RETINAL APPEARANCES

All patients showed the ophthalmoscopic appearances of venous stasis retinopathy as previously described. These comprised peripheral blot haemorrhages, microaneurysms, and venous dilatation and 'beading' (Figs. 1A,B). Laminar streaming giving the appearance of red borders to the major veins was noted in some patients. In all cases the pressure in the central retinal artery was reduced, so that the artery collapsed with minimal digital pressure on the globe.

Fluorescein angiography demonstrated many peripheral microaneurysms which could not be seen with the direct ophthalmoscope. There was marked prolongation of arteriovenous transit times and venous leakage from veins near the posterior pole in two cases (Figs. 1C-E). Patchy regions of non-filling were evident in the choroidal circulation.

\section{ANGIOGRAPHY}

The results of angiography, either by arch angiography with retrograde arterial catheterisation (four patients) or by the intravenous digital subtraction technique (three patients) are shown in Table 1 . The intravenous method gave satisfactory visualisation of the extracranial arteries in each case.

\section{ELECTROPHYSIOLOGICAL TESTS}

The standard ERG parameters ${ }^{3}$ in four patients with unilateral symptoms showed constant minor abnormalities on the affected side (Table 2). In one patient who had attacks in both eyes no difference was apparent.

The $b$ wave of the ERG evoked by flashes of equal intensity increases in amplitude with time in the dark, reaching a plateau level, but falls practically to zero when the eye is exposed to a bright photoflood lamp

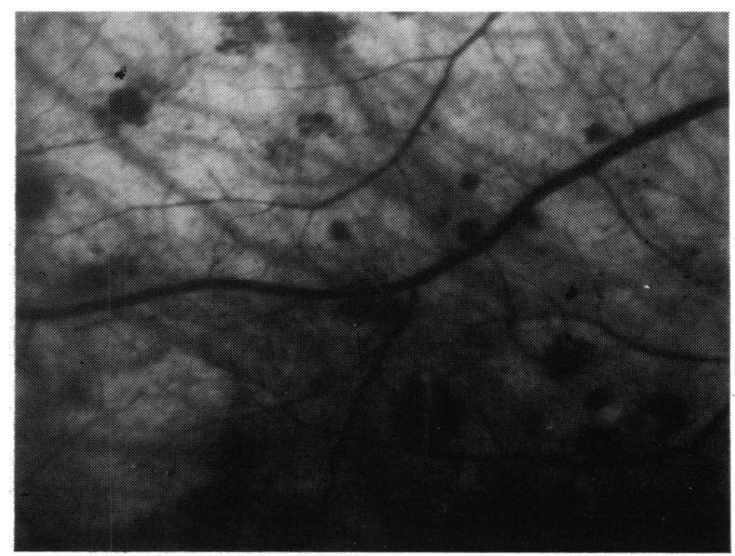

Fig. 1B Retinal periphery showing multiple round haemorrhages. 


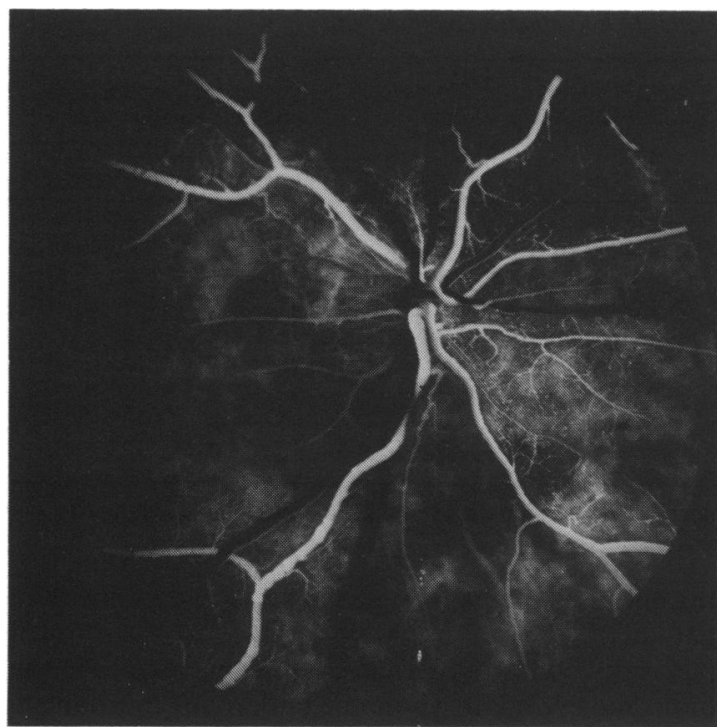

Fig. 1C Fluorescein angiography (late arterial phase) showing delayed venous filling, arterial beading (lower temporal branch), microaneurysms, and patchy choroidal filling.

for 30 seconds. Recovery of the previous b wave amplitude takes place gradually over the subsequent 10-12 minutes in a normal eye.

In all four patients with unilateral symptoms there was a marked prolongation of the time taken after photostress to regain the previous $b$ wave amplitude in the affected eye when compared with the other side (Table 3). A single patient with attacks in either eye showed a smaller difference.

In addition the light induced change in the corneofundal potential was determined by electrooculographic (EOG) methods in four out of the five patients on whom the ERG photostress tests were carried out (Table 4). The light peak of the EOG is generated by the slow increase in transpigment epithelial potential after photoreceptor response to light and is a measure of functional integrity of choroid, pigment epithelium, and photoreceptors. The EOG light rise was lower and the peak time longer in the affected eyes than in the comparison (less affected) eyes in all patients, though the number of cases was small and the difference was not statistically significant.

\section{OTHER CLINICAL FEATURES}

Two patients (Table 1) had abnormal pupils. These were large, circular, and reacted slowly both to light and to convergence. Both of these patients had attacks of visual loss on exposure to bright light. Six of the seven patients had cerebral symptoms. In three these consisted only of transient cerebral ischaemic

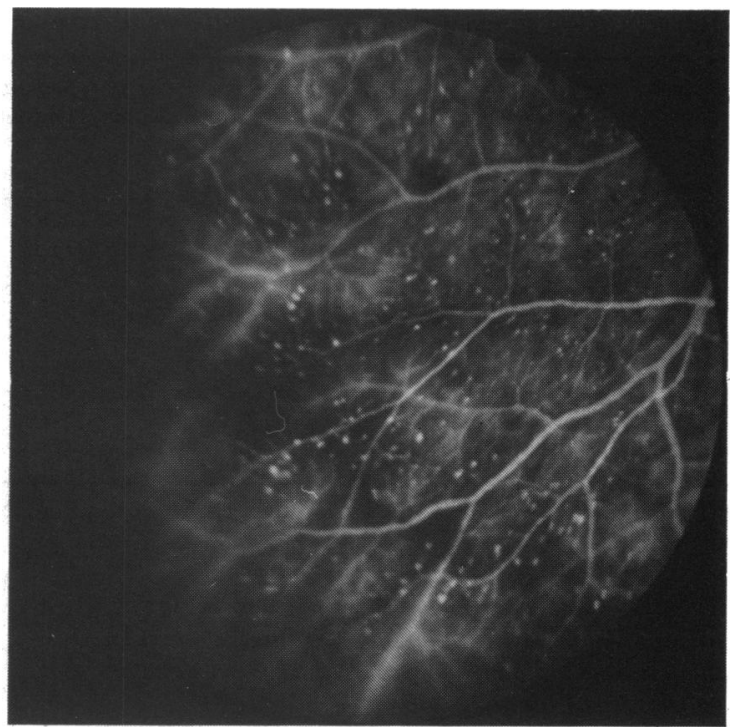

Fig. 1D Fluorescein angiogram (capillary phase) showing many capillary microaneurysms adjacent to arterioles and leakage of dye from venules.

attacks, in two there were ischaemic attacks in addition to a minor stroke. In all cases the affected hemisphere was on the same side as the carotid occlusion. The patients who sustained permanent deficits showed areas of localised cerebral infarction on CT scan. These were situated in the parietooccipital border zone between middle and posterior cerebral artery territories.

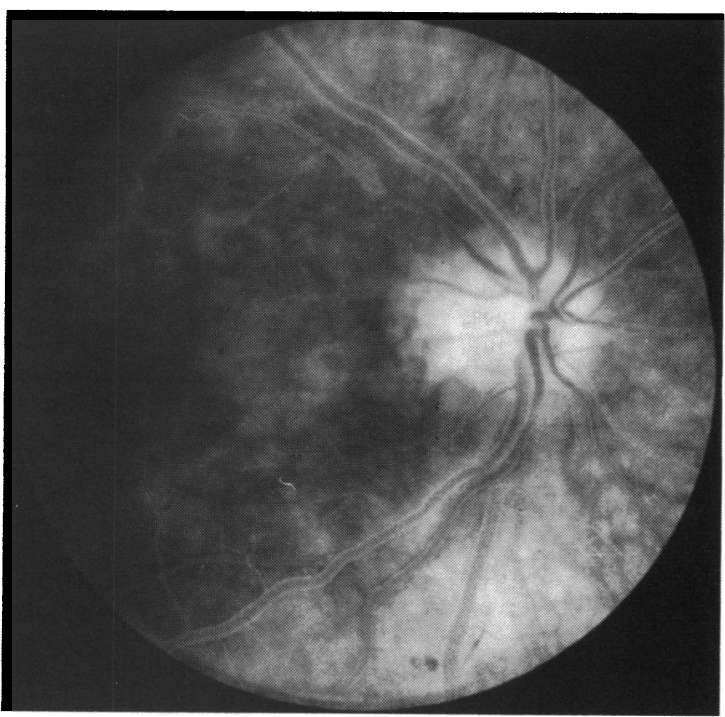

Fig. 1E Fluorescein angiogram (residual phase) showing abnormal leakage from optic disc and round large veins. 
Table 2 ERG parameters in four patients (bilateral recording). Patient 3 had attacks on either side

\begin{tabular}{|c|c|c|c|c|c|c|c|c|c|}
\hline \multirow[t]{2}{*}{ Patient } & \multirow[t]{2}{*}{ Sex } & \multirow[t]{2}{*}{ Age } & \multirow[t]{2}{*}{$\begin{array}{l}\text { Affected } \\
\text { eye }\end{array}$} & \multirow[t]{2}{*}{$\begin{array}{l}\text { Slope of ERGs } \\
\text { dark adaptation }\end{array}$} & \multirow[t]{2}{*}{$\begin{array}{l}\text { Scotopic b wave } \\
\text { threshold }\end{array}$} & \multirow[t]{2}{*}{$\begin{array}{l}\text { Maximum } \\
\text { b wave }(\mu V)\end{array}$} & \multirow[t]{2}{*}{$\begin{array}{l}\text { blawave } \\
\text { ratio }\end{array}$} & \multicolumn{2}{|c|}{$\begin{array}{l}\text { Flicker ERG wavelets } \\
\text { amplitude }(\mu V) \text { at } 30 \mathrm{~Hz}\end{array}$} \\
\hline & & & & & & & & Deepred & Bright white \\
\hline \multicolumn{4}{|c|}{ Lower limit of normal range } & $1 \cdot 2$ & $4 \cdot 7$ & 520 & $2 \cdot 3$ & 75 & 175 \\
\hline \multirow[t]{2}{*}{5} & $\mathrm{~F}$ & 72 & $\mathrm{RE}$ & R $1 \cdot 0$ & $1 \cdot 7$ & 400 & 1.6 & 25 & 50 \\
\hline & & & & L $1 \cdot 2$ & $4 \cdot 2$ & 450 & $1 \cdot 8$ & 50 & 100 \\
\hline \multirow[t]{2}{*}{1} & $\mathbf{M}$ & 70 & LE & R 0.9 & $4 \cdot 0$ & 320 & $2 \cdot 0$ & 20 & 50 \\
\hline & & & & L 0.7 & $3 \cdot 5$ & 220 & 1.8 & 2 & 20 \\
\hline \multirow[t]{2}{*}{4} & $\mathbf{M}$ & 62 & LE & R $1 \cdot 0$ & $4 \cdot 7$ & 400 & $2 \cdot 0$ & 70 & 120 \\
\hline & & & & L 0.8 & $4 \cdot 0$ & 300 & $1 \cdot 8$ & 50 & 70 \\
\hline 3 & $\mathbf{M}$ & 72 & & R 1.0 & $4 \cdot 7$ & 500 & $1 \cdot 2$ & 60 & 125 \\
\hline \multicolumn{2}{|c|}{ bilat. $L>R$} & & & L 0.9 & 4.7 & 550 & $1 \cdot 2$ & 60 & 125 \\
\hline
\end{tabular}

*The value of neutral density filter in $\log$ units when used to reduce the intensity of $R$ stimulus flash to evoke just measurable scotopic $b$ wave of the ERG.

Table 3 b Wave recovery time in five patients with low pressure retinopathy (bilateral recording). Patient 3 had bilateral attacks. Left was worse than right. The right was considered as comparison

\begin{tabular}{lll}
\hline Patient & Comparisoneyes & Affected eyes \\
\hline 5 & $12 \mathrm{~min}$ & $18 \mathrm{~min}$ \\
1 & $16 \mathrm{~min}$ & $22 \mathrm{~min}$ \\
4 & $11 \mathrm{~min}$ & $20 \mathrm{~min}$ \\
2 & $18 \mathrm{~min}$ & $24 \mathrm{~min}$ \\
3 & $18 \mathrm{~min}$ & $21 \mathrm{~min}$ \\
\hline Mean & $15.0 \mathrm{~min}$ & $21.0 \mathrm{~min}$ \\
SEM & $1.5 \mathrm{~min}$ & $1.0 \mathrm{~min}$ \\
\hline
\end{tabular}

$\mathrm{p}<0.01$ (Student's paired $t$ test).

Table 4 EOG light rise and light peak time in four of five patients with low pressure retinopathy listed in Table 3. (The lowest limit of normal EOG light rise is $250 \%$ and peak time between 7 and 9 minutes)

\begin{tabular}{llr}
\hline Patient & $\begin{array}{l}\text { Comparison eyes, } \\
\text { light rise in } \%^{*} \text { (peak time) }\end{array}$ & Affected eyes \\
\hline 1 & $170 \%(10 \mathrm{~min})$ & $136 \%(11 \mathrm{~min})$ \\
4 & $250 \%(9 \mathrm{~min})$ & $220 \%(10 \mathrm{~min})$ \\
2 & $170 \%(9 \mathrm{~min})$ & $133 \%(10 \mathrm{~min})$ \\
3 & $205 \%(10 \mathrm{~min})$ & $190 \%(12 \mathrm{~min})$ \\
\hline Mean & $199 \% 9.5 \mathrm{~min}$ & $170 \% 10.8 \mathrm{~min}$ \\
SEM & $19 \% 0.3 \mathrm{~min}$ & $21 \% \quad 0.5 \mathrm{~min}$ \\
\hline
\end{tabular}

EOG light rise $\mathrm{p}>0.05$ (NS). Peak time $\mathrm{p}<0.05$.

*The light rise is calculated by the formula:

$$
\frac{\text { Peak potential in light }}{\text { Main potential in dark }} \times 100 \text {. }
$$

\section{Discussion}

Brief attacks of retinal or cerebral ischaemia are a well known feature of atheromatous disease of the internal carotid artery, and both clinical and pathological evidence points to embolism of mural thrombus as the likely mechanism in the majority of patients. ${ }^{4}$ The present report concerns a group of patients who also experience ischaemic attacks in the brain and eye but in whom the underlying mechanism is different and is caused by a local breakdown in vascular homoeostasis (retinocerebral insufficiency).

The main differences between embolic and insufficiency attacks are in the duration, the clinical expression, and the circumstances in which they occur. An embolic attack consists of the random occurrence of a black or dense cloud rapidly spreading in a vertical direction over the whole or half of the field of vision, persisting for a few minutes, and occurring without systemic or cerebral symptoms. Insufficiency attacks on the other hand are generally of a longer duration, less rapid onset, and may be accompanied by symptoms of generalised or localised cerebral oligaemia in the form of faintness, focal weakness, or jerking of the limbs. ${ }^{5}$ The visual disturbance is described in terms of distortion or fragmentation of the field of vision, often with dazzling. The 'shutter' effect which is characteristic of embolic occlusion seldom occurs, though some patients may describe centripetal contraction of the field. Provocation by circumstances which either reduce retinal arterial pressure or raise retinal venous or intraocular pressure is a feature of insufficiency in some patients. These circumstances include rapidly standing upright, beginning to walk, stooping, movements of the neck, or sustained upward gaze. Provocation by bright light is a special feature of retinal insufficiency and is discussed below.

\section{OCULAR FINDINGS}

The present report confirms the descriptions already given of venous stasis retinopathy.' In addition to the main features of venous dilatation, peripheral haemorrhages, and microaneurysms we noted arterial irregularity (Fig. 1C) and laminar streaming of red venous blood in some of the larger retinal 
veins, possibly an indication of uneven rates of flow through different retinal regions or a disturbance of the normal coupling between flow and metabolism. A similar appearance has been described in the pial circulation in states of acute ischaemia. ${ }^{6}$ Fluorescein angiography demonstrates perivenous leakage at the posterior pole, and many clusters of peripheral microaneurysms which could not be discerned through the ophthalmoscope (Fig. 1C). A simple bedside estimation of ophthalmic artery pressure by digital pressure on the globe showed a gross reduction in all cases, and this constitutes the single most important diagnostic physical sign. We found the pressure too low for reliable ophthalmodynamometry.

\section{ANGIOGRAPHY}

The existence of four large low-resistance arteries supplying the brain allows occlusion of a single vessel to occur without a major reduction in total cerebral blood flow. When the internal carotid artery is occluded, there are two major alternative pathways: firstly, the contralateral internal carotid via the circle of Willis, and secondly the ipsilateral external carotid via the orbital anastamoses. In all but one of the present series in addition to complete occlusion of the internal carotid artery there was occlusion of other vessels, compromising one or both of these collateral pathways. Only one patient was found to have an isolated occlusion of the internal carotid artery, and it must be presumed in this case that there was incomplete development of the anterior part of the circle of Willis, with aplasia or hypoplasia of the anterior cerebral artery on one side.

\section{PATHOGENESIS}

Electrophysiological testing on patients whose attacks affected one eye and in whom the other eye acted as a control gave some insight into the mechanism of retinal insufficiency. Minor differences in the ERG in the form of scotopic b wave threshold, slope of ERG, or reduced b wave amplitude were seen and were consistently more marked on the affected side. The finding that EOG light rise was significantly lower (mean 170\%) and slower $(10 \cdot 8$ minutes) than normal ( $250 \%, 7-9$ minutes) suggests that the physiological lesion is already present at the interface between choroid, pigment epithelium, and photoreceptor outer segment in these patients with low pressure retinopathy. However, the most helpful diagnostic test was the comparison of the time taken in each eye for recovery of the amplitude of the b wave following exposure of the eye to photostress. Prolongation of the recovery time by over three minutes was found in all patients having unilateral attacks.
Two possible interpretations of these findings are suggested. The first is that resynthesis of visual pigment after bleaching causes an increase in retinal metabolic rate, and when the supply of oxygen or substrate cannot keep pace with metabolic demand the time needed to recover from photostress is prolonged. ${ }^{7}$ There is a close analogy here with angina pectoris or intermittent claudication. However, there is little evidence that retinal metabolic requirements do change significantly in different light conditions, ${ }^{8}$ and an alternative explanation may simply be that the delayed recovery after photostress is a non-specific finding, indicating mild but permanent damage to the outer retinal layers and pigment epithelium. Indeed the light evoked electrical responses of the retinal pigment epithelium and photoreceptors are extremely sensitive to hypoxia and show slower and less complete recovery." The question may be resolved by applying the test to other types of retinal disease not caused by arterial insufficiency or by repeating the test after vascular insufficiency has been corrected.

The time taken to recover normal visual acuity after exposure to photostress is a clinical measurement which has been used in the diagnosis of macular disorders and in differentiating retinal from optic nerve disease. " This test has not been systematically studied in patients with ischaemic retinal disorders, although sporadic reports have found it to be less sensitive than abnormalities of the scotopic ERG.' This simple test, in addition to the ERG b wave recovery time, deserves wider investigation both in the diagnosis of early unilateral low pressure retinopathy and in assessing the response to surgical treatment by revascularisation. ${ }^{11}$

We are grateful to Mr Jonathan Robbins and Mrs Janet Turner for assisting in the EOG and ERG recordings and to the Special Trustees of St Thomas's Hospital for financial support.

\section{References}

1 Kearns TP, Hollenhorst RW. Venous stasis retinopathy of occlusive disease in the carotid artery. Mayo Clin Proc 1963; 38: 304-12.

2 Knox DL. Ischaemic ocular inflammation. Am J Ophthalmol 1965; 60: 995-1002.

3 Ikeda H. Clinical electroretinography. In: Halliday AM, ed. Evoked potentials in clinical testing. London: Churchill Livingston, 1982: 121-47.

4 Gunning AJ, Pickering GW, Robb-Smith AHT, Russell RWR Mural thrombosis of the internal carotid artery and subsequent embolism. QJ Med 1964; 33: 155-94.

5 Russell RWR, Page NGR. Critical perfusion of brain and retina. Brain 1983; 106: 419-34.

6 Russell RWR. A study of the microcirculation in experimental cerebral embolism. Angiologia 1966; 3: 240-58.

7 Furlan AJ, Whisnant JP, Kearns TP. Unilateral visual loss in bright light: an unusual symptom of carotid artery occlusive disease. Arch Neurol 1979; 36: 375-6.

8 Feke GT, Zukerman R, Green GJ, Weiter JJ. Response of 
human retinal blood flow to light and dark. Invest Ophthalmol Vis Sci 1983; 24: 136-41.

9 Linsenmeier RA, Steinberg PH. Effect of hypoxia on potassium homeostasis and pigment epithelial cells in the cat retina. J Gen Physiol 1984; 84: 945-70.

10 Glaser JS, Savino PJ, Summers KD, McDonald SA, Knighton RW. The photostress recovery test in the clinical assessment of visual function. Am J Ophthalmol 1977; 83: 255-60.
11 Neupert JP, Brubaker RF, Kearns TP, Sundt TM. Rapid resolution of venous stasis retinopathy after carotid endarterectomy. Am J Ophthalmol 1976; 81: 600-2.

12 Kearns TP, Young BR, Piepgpas DG. Resolution of venous stasis retinopathy after carotid bypass surgery. Mayo Clin Proc $1980 ; 55: 342-6$.

Accepted for publication 16 December 1985. 